\title{
Frequência x Evasão: Proposta de protótipo para detecção de alunos em sala de aula.
}

\author{
Prof. Msc. Ubirajara C. L. Junior ${ }^{1}$, Prof ${ }^{\text {a }}$. Msc. Mônica Farias. M. Vicente ${ }^{1}$ \\ ${ }^{1}$ Instituto Federal de Educação, Ciência e Tecnologia da Bahia (IFBA) \\ Juazeiro - BA - Brasil \\ \{ubirajara.lima,monica_farias\}@ifba.edu.br
}

\begin{abstract}
School dropout is a challenge for the management of public schools, therefore it is necessary a procedure that allows the control and management of this process. The aim of this work is to put into practice a proposal for the automation of student attendance record through Arduino microcontroller and radio frequency tags (RFID), at Federal Institute of Education, Science and Technology of Bahia (IFBA), campus Juazeiro, with the intention of implementing a plan of action against school dropout.
\end{abstract}

Resumo. A evasão é um desafio para a gestão de escolas públicas, por isso torna-se necessário um procedimento que permita o controle $e$ o gerenciamento desse processo. Este trabalho tem por objetivo colocar em prática uma proposta de automação de registro de frequência de alunos através de microcontrolador Arduino e etiquetas de rádio frequência (RFID), no Instituto Federal de Educação, Ciência e Tecnologia da Bahia (IFBA), Campus Juazeiro, com o intuito de realizar um plano de ação contra a evasão escolar.

\section{Introdução}

A automação atualmente desempenha um papel importante em nossas vidas, desde o uso do controle remoto auxiliando pessoas com alguma deficiência, na execução de alguma tarefa que seja considerável simples, ou mesmo na segurança.

Conforme Dias e Pizzolato [2004], a Domótica é a integração dos serviços e tecnologias aplicados a residências, apartamentos e casas, com o propósito de automatiza-las, gerenciando energia, água, iluminação, comunicação, climatização, dentre outros, através de um computador ou mesmo de um smartphone. Levando em consideração dados do International Data Corporation (IDC) e Associação Brasileira da Indrústria Elétrica e Eletrônica (Abinne) [Teleco, 2015], que no segundo trimestre de 2015 foram vendidos 11,3 milhões de smartphones no Brasil, tem-se um campo aberto para inserção de um novo olhar para a automação.

O processo de automação residencial pode ser aplicado em sala de aula para realizar o controle de iluminação, de temperatura e até da frequência dos discentes. Segundo Chaudhari, et al, (2015), a automação neste espaço pode ser uma interface remota para diversos dispositivos dispostos nela, para isso, todos os dispositivos envolvidos neste processo estariam interligados através da rede de computadores, seja ela cabeada ou sem fio. Nesta composição o uso de um microcontrolador de entrada e 
saída, Arduino, tecnologia de baixo custo que pode ser usada na concepção de projetos de automação, será utilizado como base do projeto, que por sua vez representa uma plataforma aberta. Ele interage com o meio externo através de sensores (temperatura, umidade, gases) que captam as informações do ambiente e lhes são repassadas, fazendo este, o tratamento das mesmas.

O objetivo desta proposta é realizar a automação de frequência/monitoramento dos alunos em sala de aula com componentes de baixo custo para que se tenha uma ação, realizada pela gestão da escola, no sentido de atacar um ponto da evasão escolar.

\section{Estado da arte no âmbito da frequência discente}

De acordo com Ghodekar et.al. (2013), o registro da ausência dos alunos em sala de aula na universidade é de grande importância, visto que o estudante, ao obter uma nota no conselho final, leva-se em consideração seu histórico de ausências. O autor ainda afirma que o processo de checar quais alunos estão presentes, ou seja, chamar nome e sobrenome de cada, perde-se, pelo menos, 10 minutos para concluir tal procedimento.

O método de lista de frequência demanda tempo e é falho, pois deve ser levado em consideração que algum aluno pode não assinar e, em caso extremo, outro pode escrever o nome do que está ausente. Desta forma, o autor propõe um sistema automatizado de frequência, utilizando etiquetas RFID (Radio Frequência de Identificação) através de um cartão inteligente.

A ideia é que cada aluno porte um cartão com a sua identificação e, consequentemente, o apresente em sala de aula, uma vez que em cada sala existirá uma etiqueta de leitura. Desta forma, o sistema irá contabilizar quantos estudantes estão presentes e quantos ausentes, e toda esta informação será armazenada em um banco de dados MYSQL. A implementação deste sistema pelo autor utiliza a linguagem de desenvolvimento JAVA para codificar o software, e a utilização do SGBD (Sistema de Gerenciamento de Banco de Dados) para armazenar as informações oriundas dos cartões dos alunos.

Da mesma forma Chang (2011) afirma que no decorrer da aula os estudantes vão deixando a sala, sendo impossível ter $100 \%$ deles até o final, e propõe um sistema de registro de frequência com uma abordagem diferente. $\mathrm{O}$ autor sugere um painel em que os alunos insiram os seus cartões RFID no início e o final da aula, sendo recolhidos após esta. É interessante observar que Chang identifica que no método de chamada por frequência o professor gastava entre 5 e 10 minutos para finalizar o procedimento, situação semelhante a apontada por Ghodekar et.al..

Um estudo de caso desenvolvido na Universidade de Chang Jung Christian em Taiwan, com 2400 estudantes e 100 salas de aula. O processo de desenvolvimento foi divido em três etapas: avaliação do cenário, planejamento de sistema e testes, e verificação. Em cada sala foi instalado um painel com slots para a alocação dos cartões disponibilizados para os alunos, e este painel conectado à rede local da instituição. Assim que eles adentravam em sala, colocavam o cartão no painel e só o retiravam no final da aula. Desta forma, o professor conseguia a permanência dos alunos.

Chang afirma que esta solução ajudaria a diminuir a taxa de ausência de $30 \%$ para 5\%, auxiliando os alunos da graduação a serem bem-sucedidos ao final do semestre em relação às suas frequências. 
A automação em sala de aula é situação já proposta por alguns autores, porém Islam, et.al (2013) indica automatizar a presença dos estudantes através de cartões de identificação utilizando código de barras, e da mesma forma realizar o controle de luzes, ventiladores e outros aparatos. $\mathrm{O}$ autor ainda afirma que existem duas maneiras de realizar o registro da frequência dos estudantes em salas, sendo a primeira, o professor chamando o aluno pelo nome e depois registrando na caderneta. A segunda seria através de uma lista para que os estudantes assinem o seu nome. Em ambas as formas o professor perde em tempo para realizar esse procedimento, afirma.

O autor supracitado utiliza-se de um leitor de código de barras e o Microsoft Excel 2003, ou superior, codificando o sistema na linguagem Visual Basic (VBA). Neste sistema existe funcionalidade tais como: "login", função na qual há a leitura de código de barras do estudante e armazenamento da identificação, juntamente com a data e a hora; a função "ausente", que permite o professor marcar todos os ausentes com apenas um click; a função para calcular o número total de ausência, e o total de número de presença. O ainda autor afirma que se utilizou do Microsoft Excel por ser de fácil utilização e que a maioria dos usuários envolvidos diretamente tem usabilidade no software supracitado.

\section{SISTEMA AUTÔNOMO PARA MONITORAMENTO DE FREQUÊNCIA DE ESTUDANTES DO IFBA CAMPUS JUAZEIRO}

O Instituto Federal de Educação, Ciência e Tecnologia da Bahia (IFBA), Campus Juazeiro, tem apenas dois anos de inaugurado, mas funcionou, há quatro anos, como Núcleo Avançado gerenciado pelo Campus de Paulo Afonso.

Neste interstício, foi constatado que sempre no início de cada semestre/ano letivo, alguns estudantes começam o curso para qual prestou seleção, e após certo tempo o mesmo deixa de frequentar as aulas sem nenhuma comunicação a instituição. No modo atual, o professor não tem o conhecimento porque o aluno parou de frequentar, pois, nenhuma comunicação é realizada entre o setor responsável e o docente.

Em entrevista realizada com servidores do setor de registro de notas (CORES), que é também responsável pelo acompanhamento da frequência dos alunos, ficou constatado que este departamento apenas tem a noção que os discentes não estão frequentando quando elaboram o boletim ao final de cada unidade letiva. Esta é uma forma tardia de tentar "resgatar" um aluno que abandonou ou desistiu do curso. Tal percepção demorada pode gerar quantidade elevadas de ausências não justificadas, acarretando consequentemente a reprovação por falta, visto que as normas pedagógicas permitem apenas $25 \%$ de falta com relação à carga horária da disciplina.

De acordo com o Projeto Pedagógico Institucional do IFBA (PPI IFBA, 2013) há um compromisso de atuação pautada na democratização do acesso e permanência. Com relação à permanência deste aluno, o documento descreve algumas ações, dentre elas: "Desenvolver estudos nos Campi para identificar as causas da evasão escolar com o objetivo de desenvolver políticas locais". Diante deste tópico, percebe-se que a proposta deste projeto está respaldada na própria legislação interna do IFBA.

A proposta de protótipo para apuração de frequência de alunos em sala de aula consiste na utilização de equipamentos de baixo custo. Para registrar a presença utilizarse-á um microcontrolador Arduino, acoplado com um Shields leitor de etiquetas de rádio frequência (RFID) e etiquetas RFID, esta última, distribuídas para os alunos da 
turma da disciplina Tecnologia da Informação, armazenado o código de identificação de cada um. Para o armazenamento dos dados gerados, será utilizado o banco de dados MySQL e um sistema implementado na linguagem PHP, o qual permitirá gerenciar, via Web, e contabilizar a presença, juntamente com outros dados, a exemplo dia e hora.

O sistema irá disparar um alerta para o setor responsável através de um e-mail, o qual ficará condicionado a 3 faltas consecutivas e/ou quando chegar próximo do limite de faltas permitido pela disciplina. O e-mail informará o nome do aluno, turma, dias faltosos e quantidade de faltas contida na disciplina até a presente data. A quantidade de faltas para o envio da mensagem foi escolhida pelo fato de que muitas disciplinas têm 2 aulas na mesma semana, neste caso, gerando 2 faltas. Assim, se o aluno se ausentar na semana subsequente, o e-mail automaticamente será disparado.

A partir da rotina da gestão escolar, a mesma poderá entrar com um plano de ação para contactar o aluno faltoso e possa apurar o motivo dos dias faltosos.

\section{Considerações Finais}

O protótipo de automação de sala de aula a ser implementado, fortalece o uso de plataforma de prototipagem eletrônica de baixo custo, uma possível resolução de um problema identificado, além de atender ao requisito indicado pelo projeto pedagógico do IFBA. Apesar de o sistema ser inicialmente implementado apenas para uma turma, pretende-se trabalhar para realizar a implantação em todas as turmas do Instituto. Etapas futuras são vislumbradas para a inserção de um aplicativo para dispositivos móveis, no qual os alunos possam, também, acompanhar a sua assiduidade em sala de aula.

\section{Referências}

DIAS, C. L. A.; PIZZOLATO, N. D.; DOMÓTICA - Aplicabilidade e Sistemas de Automação Residencial. Revista Vértices - Instituto Federal de Educação, Ciência e Tecnologia Fluminense. Vol 6. p. 10-32. 2004.

TELECO, http://www.teleco.com.br/smartphone.asp. Acessado em: 19 de Novembro de 2015.

CHAUDHARI, S. B.; KHULPE, S.; PATKI, P.; KALE, K.; MALAGE, D.; Classroom Automation using Voice Commands. International Journal for Science and Advance Research in Technologu - IJSART. Vol. 1. p.76-78. 2015.

PPI IFBA - Projeto Pedagógico Institucional. Disponível em: www.ifba.edu.br Acessado em: 14 de Março de 2017.

GHODEKAR, Vaishali; KUTE, Aboli; PATIL, Swati; THAKUR, Ritesh; Automated Attendance system with RFID through smart card. International Journal of Engineering Research e technology - IJERT. Vol. 2. p. 2724-2728. 2013.

CHANG, C. H.; Smart Classroom Roll Caller System with IOT Architecture. Second International Conference on Innovation in Bio-inspired Computing and Application. IEEE Computer Society. p. 356-260. 2011.

ISLAM, N; TABASSUM, F; SARKER, G. K.; SEN, D; Intelligent Classroom Management System. Monografia do curso de Ciência em Elétrica e Engenharia Eletrônica. Universidade Brac - Bangladesh. 2013 